\title{
La articulación de la indignación del pueblo catalán: rasgos populistas en la Candidatura d'Unitat Popular (CUP)
}

\author{
Articulating the indignation of the Catalan people: populist traits in \\ the Candidatura d'Unitat Popular (CUP)
}

\author{
TOBIAS THYBO \\ Universidad de Aarhus \\ tobias.thybo@hotmail.com
}

Resumen: Este artículo analiza los rasgos populistas en el discurso político de la Candidatura d'Unitat Popular (CUP), partido independentista de la izquierda radical catalán. Primero, se analiza el éxito de la CUP ubicando al partido en lo que se llamará una competencia de populismos en los años más recientes. En este sentido, el movimiento nacionalista se describe como una catálisis para las ideas populistas en Cataluña. Específicamente, el artículo argumenta que la presencia del partido en el panorama político catalán se deja explicar por la manera en que el nacionalismo catalán se articula como un nacionalismo de rupturas. Esta especie de lenguaje populista también es similar al del partido español Podemos, cuyo impacto sobre el discurso de izquierda pone cierta presión sobre la narrativa anti-capitalista tradicional. En este contexto, se argumenta que la CUP ofrece una alternativa radical que encuentra su fundamento normativo en el pueblo catalán, y que precisamente por el hecho de insistir en la dicotomía izquierda-derecha, hasta cierto punto, ha conseguido asumir el descontento de tantos catalanes.

Palabras clave: populismo de izquierda, nacionalismo, independencia, Cataluña, CUP.

Abstract: This article analyses populist traits in the political discourse of the Catalan left-wing pro-independence party Candidatura d'Unitat Popular (CUP). First, the article analyses the success of the CUP by placing the party in what is deemed a competition of populisms in recent years in Catalonia. As such, the nationalist movement is described as a catalyst for populist ideas in Catalonia. Specifically, it will be argued that the presence the party has had in the political panorama of Catalonia can be explained by the way in which Catalan nationalism has been expressed as a nationalism of rupture. This kind of populist language is also similar to that of the Spanish party Podemos, whose lasting effect on leftist discourse puts a certain pressure on the traditional anti-capitalist narrative. In this light, the article argues that the CUP offers a radical alternative which finds its normative foundation in the Catalan people, and that precisely by insisting on the leftright dichotomy it has, to a certain extent, been able to absorb the discontent of many Catalans.

Recibido: 13 de mayo de 2019; aceptado: 26 de julio de 2019; publicado: 30 de septiembre de 2019 Revista Historia Autónoma, 15 (2019), pp. 189-205

e-ISSN: 2254-8726; DOI: https://doi.org/10.15366/rha2019.15.010 
Keywords: Leftist populism, nationalism, independence, Catalonia, CUP.

\section{Introducción}

El partido español Podemos se ha llevado la mayor parte de la atención académica sobre la izquierda española en los años más recientes ${ }^{1}$. Y con razón, dado el éxito del partido ya en sus primeras elecciones parlamentarias en 2015 y la influencia que sigue ejerciendo sobre el pensamiento en la izquierda política no solo en España, sino también en el resto de Europa. Podemos destaca por las reflexiones teóricas que fundamentan su organización y hasta cierto punto sus propuestas políticas. Como veremos, el partido asumió un discurso populista de una forma consciente con la intención de subvertir la dicotomía izquierda-derecha política y tomar una posición central en el panorama político español. Lo hizo en gran parte basándose en las aportaciones teóricas de Ernesto Laclau y Chantal Mouffe sobre el populismo, por lo que el partido se convirtió en una especie de experimento político: la construcción de un nuevo sujeto del pueblo español. Una comparación directa entre los rasgos populistas de Podemos y los de la Candidatura d'Unitat Popular (CUP), partido independentista de la izquierda radical en Cataluña, sería algo insensible e injusta. Primero porque Podemos, hijo del movimiento 15-M, es un fenómeno a un tiempo local y español, mientras que la CUP se estableció en un proceso de equilibrio constante entre su política social y su lucha por la independencia de Cataluña. Desde luego Podemos no es ajeno a la cuestión de la autodeterminación de los catalanes y tiene una presencia importante en la política regional y en Barcelona. Sus raíces y su trayectoria, sin embargo, no son precisamente las mismas que la CUP. Y segundo porque la CUP, desde sus primeras elecciones parlamentarias en 2012, no deja de ser un partido situado al margen del poder político en Cataluña.

Aun así, difícilmente se pasa por alto el impacto del partido en los últimos años. Los diez escaños que obtuvo en el Parlament en 2015 le aseguraron a la CUP una posición particular que llevó a tensiones internas, pero también a movimientos importantes, como fueron, por ejemplo,

\footnotetext{
${ }^{1}$ Sobre reflexiones teóricas acerca del populismo de Podemos, véanse por ejemplo Agustín, Óscar García y Marco Briziarelli (coords.), Podemos and the New Political Political Cycle: Left-wing Populism and Anti-establishment Politics, Cham, Palgrave Macmillan, 2018. https://doi.org/10.1007/978-3-319-63432-6_12; Stoehrel, Rodrigo Ferrada, “The regime's worst nightmare: the mobilization of citizen democracy. A study of Podemos' (aesthetic) populism and the production of affect in political discourse", en Cultural Studies, 31 (2017), pp. 543-579. https://doi.org/10.1080/09502386.2016.1264004; Errejón, İñigo, "El 15-M como discurso contrahegemónico", en Encrucijadas. Revista crítica de ciencias sociales, 2 (2011), pp. 120-145; Meyenberg, Yolanda, "Disputar la democracia. El caso de Podemos en España", en Revista mexicana de ciencia políticas y sociales, 62 (2017), pp. 221-241. https://doi.org/10.1016/S0185-1918(17)30022-3; Eklundh, Emmy, "Populism, Hegemony and the Phantasmatic Sovereign: The Ties between Nationalism and Left-Wing Populism”, en Agustín, Óscar García y Marco Briziarelli (coords.), Podemos and the New... op. cit., pp. 123-146; Booth, Josh y Patrick Baert, The Dark Side of Podemos? Carl Schmitt and Contemporary Progressive Populism, Londres, Routledge, 2018. https://doi. org/10.1007/978-3-319-63432-6_6
} 
la decisión de no apoyar la investidura de Artur Mas como presidente en 2015 y el veto contra los presupuestos del Govern en 2016. Quizá más interesante, como señalan Oscar Barberà y Alberto Díaz-Montiel², la CUP mantuvo en gran medida la "complejidad organizativa" propia de los partidos movimiento a pesar de su mayor influencia política. En este sentido, la CUP, aunque tenga más similitudes que diferencias respecto de Podemos, se puede interpretar como una propuesta de la izquierda fundamentalmente diferente.

Otros han dado cuenta de la genealogía de la CUP y su estructura interna ${ }^{3}$. En este texto se analizan específicamente los rasgos populistas de la CUP en el contexto de lo que se describirá como una competencia de populismos que está teniendo lugar en Cataluña. Así, el trabajo pretende ubicar una voz importante de la izquierda radical como es la CUP en un momento histórico particular, ya que el nacionalismo catalán ha resultado extraordinariamente potente como vehículo de ciertas ideas políticas. En este contexto, se analiza y discute el alcance de la subjetividad popular representada en el discurso de la CUP. El análisis se fundamenta principalmente sobre la aportación teórica de Ernesto Laclau ${ }^{4}$ sobre el populismo como dinámica de los antagonismos políticos. Aunque es evidente que Cataluña no es el único lugar donde actualmente se puede hablar de choques de populismos, ni en España ni en el resto de Europa, también es cierto que la cuestión de la independencia se ha ido imponiendo como eje central de todas las cuestiones políticas en Cataluña. El historiador Ángel Montserrat señala que "uno de los rasgos esenciales del procés, y una de las razones de su indudable éxito, ha sido la simplificación del campo político", ya que ha convertido "en operativo un esquema dicotómico que opone soberanismo a unionismo"s. Esto es así sobre todo desde 2010, año en que se hizo pública la sentencia del Tribunal Constitucional sobre la reforma del Estatut de autonomía catalán. La sentencia despertó un fuerte descontento y desencadenó numerosas reacciones en forma de actividades sociales como las consultas populares realizadas entre 2009 y 2012 y manifestaciones masivas, todas las cuales hicieron clara la oposición entre España y Cataluña a través de la noción de la independencia. En este sentido, las causas políticas empezaron a subordinarse a la cuestión de la independencia en una dinámica básicamente populista. Esto ha dado lugar a colaboraciones políticas relativamente amplias como es el caso del gobierno catalán actual en 2019 de las dos coaliciones: Junts per Catalunya (del partido

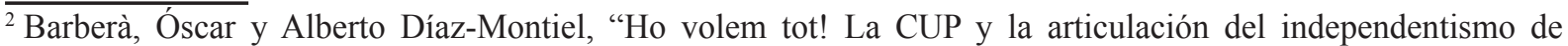
izquierda radical en Cataluña, en Revista de Estudios Políticos, 182 (2018), pp. 159-189. https://doi.org/10.18042/ cepc/rep.182.06

${ }^{3}$ Culla, Joan, El tsunami. Com i per què el sistema de partits català ha esdevingut irreconeixible, Barcelona, Raval Editions, 2017; Díaz-Montiel, Alberto, "La Candidatura de Unidad Popular (CUP): historia, estructura y model originario, en Política y gobernanza", en Revista de investigaciones y análisis político, 2 (2018), pp. 101-127. https://doi.org/10.30827/polygob.v0i2.7823; Barberà, Óscar, "La Candidatura d'Unitat Popular (CUP): El auge del independentismo de izquierda radical en Cataluña", en Forti, Steven et al. (coords.), El proceso separatista en Cataluña. Análisis de un pasado reciente (2006-2017), Granada, Editorial Comares, 2017, pp. 205-224; Barberà, Óscar y Alberto Díaz-Montiel, "Ho volem tot!... op. cit.

${ }^{4}$ Laclau, Ernesto, On Populist Reason, Londres, Verso, 2005.

${ }^{5}$ Montserrat, Ángel Duarte, "Buscar el calor de la casa solariega. Utopías y populismos nacionalistas para tiempos de crisis” en Forti, Steven et al. (coords.), El proceso separatista ... op. cit., p. 161.
} 
Partit Demòcrata Europeu Català -PDeCAT_ sucesor de Convergència i Unió) y la coalición Esquerra Republicana de Catalunya-Catalunya Sí.

La explicación fácil a la "vuelta a la normalidad" de la CUP en las elecciones de 2017 con cuatro escaños sería que el éxito momentáneo del partido puede explicarse por una "excepcionalidad" del momento, por un descontento general en la población catalana que se prestó al proyecto de la izquierda radical. Este trabajo analiza específicamente la representación del partido en función de los rasgos populistas que se pueden detectar en su discurso para ver hasta qué punto se alinea el populismo de la izquierda radical con las voces populistas con mayor fuerza en Cataluña en los años más recientes. En este sentido, situaremos a la CUP en su relación con dos motores del populismo: el nacionalismo catalán, fundamentalmente asociado con el establishment político, y el descontento social que Podemos buscó representar y que se ha hecho evidente no solo en Cataluña, sino en toda España. Es en este entorno complejo, esta competencia de populismos — por así llamarlo_-, en el que veremos la CUP entre los años 2010 y 2018. Se describirá cómo la CUP, aunque comparta un lenguaje populista con el nacionalismo catalán hegemónico, sigue ofreciendo una alternativa radical que tiene su fundamento normativo en el "pueblo catalán”. El trabajo pretende demostrar que al quedarse la CUP dentro de la dicotomía izquierda-derecha, ha reforzado su discurso por el contexto de conflictividad política en el que se expresa, y que esto puede explicar tanto la presencia que ha tenido en el panorama político catalán como el hecho de que actualmente se encuentre al margen de la izquierda catalana.

\section{El populismo como dinámica de la política}

Ernesto Laclau, en su libro On Populist Reason ${ }^{6}$, argumenta que el populismo, más allá de los sentidos peyorativos con los que se utiliza a menudo, puede servir para conceptualizar el propio trabajo político. La reivindicación de una causa universal, para Laclau, no debe entenderse como una estrategia perteneciente a unos sistemas ideológicos específicos, como pueden ser la izquierda o la ola reciente de nacionalismos en Europa. Antes bien, Laclau entiende el populismo como una forma de articulación de lo político. De este modo, el concepto de populismo no se alude al margen del campo político, sino al proceso de creación de sentidos que lo conforma. Por la misma razón, en vez de distinguir entre política populista y no populista, tal vez tendría más sentido hablar de grados de potencia o claridad en los discursos políticos. Cuando en este

$\overline{{ }^{6} \text { Laclau, Ernesto, }}$ On Populist Reason... op. cit. 
artículo se refiere al populismo de la CUP, entonces, es a la medida en que el partido articula sus demandas políticas en función de un antagonismo fundamental.

En esta perspectiva, el discurso populista se construye en lo que Laclau y Chantal Mouffe describen como cadenas de equivalencia: la manera en que unos sentidos "se prestan" o subordinan a otros para significar una sola cosa: "equivalence creates a second meaning which, though parasitic on the first, subverts it: the differences cancel one other out insofar as they are used to express something identical underlying them all" ". Llevando esto a los discursos políticos, las palabras que entran en equivalencia se "subordinan" a la causa universal; en el caso de la CUP, la reivindicación del propio pueblo catalán. Es un proceso en el que los sentidos hasta cierto punto pierden su particularidad para "encarnar" su causa universal. Es decir que los significados concretos prestan cuerpo a la causa universal, perdiendo en el proceso parte de su propia particularidad ${ }^{8}$.

De esto se puede afirmar que el pueblo al que los respectivos populismos aluden es difícil de definir en función de categorías económicas, culturales o sociales. Como dice Cas Mudde, teórico holandés del populismo, la diferencia entre el pueblo y la élite es normativa, no empírica9. Significativamente, Cas Mudde ya en 2004 describía algo así como un "zeitgeist populista", animado en parte por la "depolitización" de las democracias en Europa ${ }^{10}$. El populismo se formula como una respuesta a lo que se percibe como una falta de representación y subjetividad política. Esta idea también es central en Laclau y Mouffe que insisten en la cualidad no esencial del sujeto político. Mouffe, en su libro For a left populism ${ }^{11}$, dirige una crítica hacia las izquierdas europeas por no pensar en un pueblo identificado más allá de las categorías sociológicas tradicionales del marxismo. Contra definiciones más positivistas como la "multitud" descrita por Michael Hardt y Antonio Negri' ${ }^{12}$, el pueblo, insiste Mouffe, no se descubre, sino que se crea a través de una formación discursiva hegemónica. Mouffe argumenta que esto, junto con la aparición en las últimas décadas de varias demandas sociales no necesariamente relacionadas con la "clase trabajadora", hace que un populismo de izquierda deba proyectarse hacia una representación de demandas distintas bajo un pueblo democrático.

Aunque veremos que esta perspectiva teórica ayuda a explicar en parte el éxito de la CUP en los años más recientes, cabe decir aquí que el argumento de este artículo no es que la CUP en su totalidad sea un partido populista según la definición de Cas Mudde. Como éste bien indica, los populismos se identifican por un carácter reformista, no revolucionario. Según Joan Culla, a partir del nuevo siglo las CUP consiguieron —en palabras de un veterano del

\footnotetext{
${ }^{7}$ Ibídem, p. 127.

${ }^{8}$ Laclau, Ernesto, "Por qué construir un pueblo es la tarea principal de la política radical", en Cuadernos del CENDES, 23 (2006), p. 6.

${ }^{9}$ Mudde, Cas, “The Populist Zeitgeist”, en Government and Opposition, 39 (2004), p. 544. https://doi.org/10.1111/ j.1477-7053.2004.00135.x

${ }^{10}$ Ibídem.

${ }^{11}$ Mouffe, Chantal, For a left populism, Londres, Verso, 2018.

${ }^{12}$ Hardt, Michael y Antonio Negri, Multitude: War and Democracy in the Age of Empire, Nueva York, The Penguin Press, 2004.
} 
partido - “agrupar, en l'àmbit local, militants de pràcticament totes les organitzacions polítiques i sectorials de 1'Esquerra Independentista"13. Fue a través de un proceso lento de cooperación entre varias agrupaciones locales como el partido llegó a tener cierta unidad tanto en la cuestión independentista como las políticas sociales. Como argumenta Óscar Barberà, la izquierda catalana, ya desde la Transición, se encontró dispersa por la tensión entre estos dos objetivos no necesariamente complementarios ${ }^{14}$. En este contexto, y teniendo en cuenta la competencia parlamentaria de la ERC, no sorprende que la izquierda radical tardara tanto en conseguir un perfil relativamente marcado. Esto dio lugar a la "irrupción" del partido en el terreno político en las elecciones municipales de 2011, que dieron a la gente a conocer el partido. Sin duda el paso decisivo para llegar a este punto fue hacer ver que el proyecto social era inseparable de la independencia. Según Barberà, a mediados de los años noventa, un $4 \%$ de los catalanes se identificaban como catalanes y de izquierda; en 2014, el número había subido hasta el 14,5\% $\%$. En este sentido, la izquierda catalana consiguió manifestarse como una demanda democrática, resumida en la expresión siguiente recordada por Joan Culla: "Serem el cavall de Troia de les classes populars al Parlament"16. Sin embargo, incluso en este punto desde el que se empieza a apreciar el partido como un actor importante a nivel regional, la CUP mantiene su composición altamente horizontal y heterogénea. Aquí también contrasta con la importancia del liderazgo en los partidos más explícitamente populistas, aunque también es cierto que la CUP ha tenido voces carismáticas como el portavoz Carles Riera y la exdiputada Anna Gabriel i Sabaté. El enfoque de este artículo, entonces, será cómo el discurso de la CUP confluye con lo que, en palabras de Chantal Mouffe, podríamos llamar un momento populista como el que ha vivido Cataluña.

No falta quien interpreta la situación política actual en Cataluña en un contexto europeo en el que los populismos, a menudo con tintes nacionalistas, sirven como respuesta a las crisis democrática y ecónomica, y a los procesos de globalización. El historiador Diego Díaz Alonso descarta la "excepcionalidad" del proyecto independentista catalán en los últimos años para insertarlo en una narrativa que va más allá de la relación entre España y Cataluña: “el Procés [...] no es sino la expresión catalana de una crisis española, a su vez también, plenamente interconectada con la crisis económica, social y de representación que vive Europa" ${ }^{17}$. Por su parte, el politólogo Oriol Bartomeus dice del movimiento independentista que "hay que circunscribirlo a la oleada proteccionista y nacionalista que viven otros países del entorno europeo, y aún de otras latitudes"18. Y tiene sentido que un momento de crisis sea campo fértil

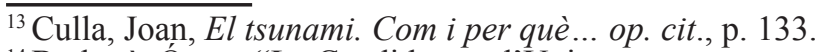

${ }^{14}$ Barberà, Óscar, "La Candidatura d'Unitat... op. cit.

${ }^{15}$ Ibídem, pp. 206-208.

${ }^{16}$ Culla, Joan, El tsunami. Com i per què... op. cit., p. 138.

${ }^{17}$ Alonso, Diego Díaz, "Tan lejos y tan cerca. España y Cataluña: entre la indignación y el independentismo", en Forti, Steven et al. (coords.), El proceso separatista... op. cit., p. 190.

${ }^{18}$ Bartomeus, Oriol, "Auge del independentismo y relieve generacional: una relación compleja”, en Forti, Steven et al. (coords.) El proceso separatista... op. cit., p. 111.
} 
para los populismos. Es en estos momentos en los que los "significantes vacíos", en palabras de Laclau, se abren a otras interpretaciones de la realidad, por lo que la noción del pueblo se disputa entre distintos intereses políticos ${ }^{19}$. Aunque este trabajo no se centrará en las similitudes que pudiera haber entre la situación en Cataluña y otros casos europeos, parece que hay una especie de lenguaje de crisis que ha dado forma a la gran mayoría de las voces políticas en Cataluña. En la primera parte del análisis se señalará cómo el nacionalismo catalán se expresa como un nacionalismo de ruptura en el que la CUP comparte un lenguaje con el establecimiento político.

\section{Metodología y alcance del análisis}

El análisis se basa en un total de 93 artículos de prensa recogidos entre 2009 y 2018, el programa electoral de la CUP en 2017 y la interpretación de algunos acontecimientos de gran valor simbólico como fueron por ejemplo las consultas populares que se organizaron entre 2009 y 2011. Los artículos varían entre noticias, entrevistas, opiniones y análisis políticos y vienen de periódicos tanto españoles como catalanes. Es cierto que la cobertura del independentismo ha sido especialmente politizada. La primera parte del análisis se centra en tendencias nacionalistas que van más allá de la izquierda catalana, por lo que no se tiene demasiado en cuenta la línea editorial en cuanto a la dicotomía izquierda-derecha. Los dos periódicos más usados para el análisis son El País y La Vanguardia. Además de ser dos de los periódicos más grandes del país, tienen sus diferencias tanto sobre el independentismo como las políticas sociales. En este sentido, se ha optado por un panorama de los medios de comunicación relativamente amplio. Aunque El País suele mantener una línea editorial más acercada a la izquierda, ninguno de los medios de prensa usados se encuentra cercano a la izquierda radical. Para tener una imagen más elaborada de la narrativa de la izquierda, la segunda parte del análisis se apoya en mayor parte en el programa electoral de la CUP. Para este trabajo también se prescinde de fuentes internacionales, aunque seguramente pudiera haber aportado una perspectiva importante, en parte por la estrategia internacional del nacionalismo catalán señalada por Lo Cascio ${ }^{20}$.

\footnotetext{
${ }^{19}$ Agustín, Óscar García y Marco Briziarelli (coords.), Podemos and the New... op. cit., p. 14.

${ }^{20}$ Lo Cascio, Paola, "In or Out? Las políticas de internacionalización del Procés catalán y la producción de discurso en torno a la independencia (2012-2016)", en Forti, Steven et al. (coords.), El proceso separatista ... op. cit., pp. 131-149.
} 
4. El procés: un nacionalismo de ruptura

El 3 de octubre 2017 se coordinó una huelga general con la participación de la ANC, Òmnium Cultural y la CUP. La huelga se convocaba en protesta por las acciones violentas de la Guardia Civil el primero de octubre de 2017 y el día fue el resultado de una colaboración amplia: en Barcelona se pararon los servicios públicos, las autovías fueron cortadas por grupos de manifestantes y hubo protestas masivas en la ciudad. Tomaron parte instituciones públicas, los partidos y militancias políticos, organizaciones sociales y personas civiles. Es significativo porque el sentido principal de la huelga es, podríamos decir, antisistema: literalmente poner fuera de función la vida cotidiana. El día tuvo el aspecto de cierto radicalismo: daba la sensación de que se estaba viviendo un momento de excepcionalidad que sirvió para que se juntaran varios actores distintos en Cataluña bajo la misma causa. No era la primera vez que el procés unía voces contrarias en otras cuestiones políticas, pero fue tal vez una de las ocasiones con mayor repercusión pública. Ya entre 2009 y 2011 el movimiento independentista hizo repercusión con la organización de consultas populares con las que se pretendía situar en primer plano la cuestión de la autodeterminación. Cerca de un millón de personas votaron con la contribución de 60.000 voluntarios. Aunque no tuvieran valor jurídico, las consultas sirvieron para radicalizar la noción de la independencia que culminó en 2017. Como dice Diego Alonso, "el éxito del independentismo ha sido lograr identificar independencia con radicalidad democrática" ${ }^{21}$. Oscar Barberà $^{22}$ señala la importancia que tuvo la CUP en la organización de las consultas.

Es un discurso establecido sobre la oposición entre el pueblo catalán y un sistema reconocido como el establecimiento político español. La CUP no es ajena a este antagonismo y se expresa en un lenguaje similar. En 2017 tuvo lugar una confrontación entre radicales de la Candidatura d'Unitat Popular (CUP) y grupos de ultraderecha en Barcelona. Se utilizó una estrategia de protección que se daba en llamar un "cordón humano" o "cordón de seguridad": personas en línea, agarradas una a la otra de los brazos ${ }^{23}$. Pocos años antes, en 2013, la Assemblea Nacional Catalana (ANC) organizó una manifestación masiva para la Diada el 11 de septiembre, la llamaban Vía Catalana. Una cadena humana se extendió desde la frontera con Francia, con la participación de hasta dos millones de personas. No hacía falta que existiera una amenaza para que el símbolo de los cordones humanos adquiriese sentido en una función esencialmente populista. El rol de la CUP en acciones como las descritas hasta ahora no ha sido marginal. Al contrario, el partido ha participado de una forma activa para fomentar el descontento civil y crear arenas donde este descontento se pudiera expresar desde una posición de izquierda

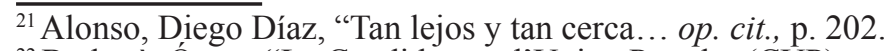

${ }^{22}$ Barberà, Óscar, "La Candidatura d'Unitat Popular (CUP)... op. cit., p. 210.

${ }^{23}$ Piñol, Ângels, "La CUP llama a proteger su sede de una protesta de la extrema derecha", en El País, 1 de diciembre 2017. «https://elpais.com/ccaa/2017/12/01/catalunya/1512147930_918402.html»[Consultado el 27 de abril de 2017].
} 
marcada. Aunque en 2007 se hablaba todavía solo de las CUP en lugar de hacerlo de la CUP, a nivel municipal — según Joan Culla—, el partido empezaba a ser el catalizador de la izquierda radical catalana: "Hi havia, doncs, un contingent difícil de precisar de vots independentistes frustrats, desitjosos d'expressar protesta i radicalitat; i, per primer cop, hi havia una opció capaç de canalitzar — en alguns indrets - aquests sentiments"24. Joan Carles Gallego del sindicato CCOO en 2012 se expresó optimista sobre la capacidad del partido de "aglutinar el movimiento independentista extra-parlamentario"25. La CUP supo expresar el estado de ánimo popular en el lema ho volem tot que, como dice Óscar Barberà, "situaba en el mismo plano la independencia y un giro copernicano en las políticas sociales"26.

La apariencia de ruptura está arraigada en la actividad a nivel civil que ha apoyado el procés y que sigue dibujando la imagen de la nación catalana. El historiador Marek Tamm, en la línea del teórico Eric Hobsbawm, hace hincapié en la importancia de la nación como algo que se (re)produce constantemente a través de actos performativos que proporcionan a las naciones una forma que no está determinada por su pasado o la "autenticidad" de las tradiciones, sino por la potencia - política, social, cultural - de estas. Los actos performativos, dice Tamm, "unites the members of the nation, confirms their individual belonging to a common community, sharing and passing on a national notion of history"27. Las consultas populares en Cataluña son un ejemplo de que la noción de independencia puede llevar a unas actuaciones de la nación muy potentes. Las consultas populares son actos performativos en un sentido simbólico, pero también práctico: gente que se congrega para manifestar su voluntad, darle presencia a una voluntad que hasta entonces tal vez sólo se había conjeturado como un descontento. En 2011 acudió el 21,3\% del censo electoral a la consulta que se celebró en Barcelona, y el resultado fue de un aplastante: 89,7\% a favor de la independencia ${ }^{28}$. El poder de las consultas está en que se pueden repetir. El significado del famoso lema "Som una nació. Nosaltres decidim" acuñado para una manifestación en 2010 puede ser definitivo, o por lo menos queda en ella la sensación de radicalidad antes mencionada, pero con las consultas es una declaración que se convierte en práctica. Como dice Clua i Fainé sobre las consultas, tienen un poder performativo en el sentido de que activan el sentido de la legitimidad: "Proclamar la voluntad de votar en sí misma daba legitimidad al derecho a votar"29. En un acto de apoyo a la consulta en Barcelona en 2011, el lingüista Joan Solà i Cortassa resume el valor performativo de esta expresión de voluntad:

\footnotetext{
${ }^{24}$ Culla, Joan, El tsunami. Com i per què ... op. cit., p. 135.

${ }^{25}$ Jòdar, Jùlia de y David Fernández, Cop de Cup. Viatge a l'ànima i a les arrels de les Candidatures d'Unitat Popular, Barcelona, Columna Edicions, 2012.

${ }^{26}$ Barberà, Óscar, "La Candidatura d’Unitat Popular (CUP)... op. cit., p. 213.

${ }^{27}$ Tamm, Marek, "How are Nations Made?", en revista de publicación desconocida, p. 142. «http://www.academia. edu/36035847/How_are_nations_made» [Consultado el 28 de mayo 2018].

${ }^{28} \mathrm{La}$ Vanguardia, "Más de 257.000 personas participan en la consulta independentista de Barcelona", en La Vanguardia, 10 de abril 2011. «http://www.lavanguardia.com/politica/20110410/54139504996/mas-de-257-000personas-participan-en-la-consulta-independentista-de-barcelona.html» [Consultado el 26 de marzo 2018].

${ }^{29}$ Clua i Fainé, Montserrat, "Identidad y política en Cataluña: el auge del independentismo en el nacionalismo catalán actual", en QUADERNS-E, 19 (2014), p. 92.
} 
"Esta consulta tiene más valor que si tuviera un valor legal, vais a votar porque queréis"30. Las consultas fueron vehículo de ese estado de ánimo, le dieron cuerpo y voz.

La CUP veía con cierta suspicacia la manera en que se "institucionalizaba" lo que había empezado en la forma de un movimiento independentista ${ }^{31}$. El partido en 2012 comentaba cómo CiU supo hacer la "interpretació política de l'estat de consciència del moviment independentista" y admitía no haber sido capaz de "curtcircuitar la capacitat de l'oligarquia política d'apropiarse [...] les pràctiques que es donen al marge d'ella a fi de desnaturalitzar-les [lemas y consignas]"32. En este sentido, si la CUP participó en este lenguaje rupturista no fue para formar una frontera homogénea. Pero tampoco tenía las herramientas para desmontar la institucionalización del independentismo por parte del centro-derecha. El partido dejaba claro que su virtud era la "perseverancia" y por ello no tenía "prou espai de reflexió per tenir o per expandir un discurs propi" ${ }^{33}$. En vez de elaborarse una teoría sobre el poder, entonces, la CUP debía apostar por una "pragmática del poder". Fue una estrategia coherente desde el punto de vista de la izquierda radical. La evolución del partido llegó a un momento importante que habla mucho de la situación de excepcionalidad que vivía Cataluña en aquel momento. En las elecciones parlamentarias de 2015, la CUP asumió la cara de esa excepcionalidad cuando obtuvo diez escaños, superando con creces las expectativas de un partido situado a la izquierda de ERC. Según Barberà, el 35 \% de los que votaron a la CUP en 2015 procedía de ERC, una movilización que no se explica por cambios políticos de la CUP. Lo cual indica que la izquierda radical pasó por una especie de normalización. Este proceso encuentra su máxima expresión en el referéndum celebrado en 2017 y la posterior aplicación del artículo 155 de la Constitución española, con la que se destituyó el Parlament de Caalunya y de facto el autogobierno. Carles Riera, líder de la CUP, dijo sobre la significación del referéndum que muchos "ciudadanos" llevaban tiempo luchando por "derechos democráticos", "derechos civiles", y que "todo esto cuajó en el referéndum". La CUP desde luego no fue sola en denunciar la reacción del gobierno español, pero fue quizás el partido que más lejos llegó en mantener una posición radical frente al gobierno central. Como dijo Maria Sirvent, criticando a ERC por no ser lo suficientemente firmes frente a la amenaza del 155: "Si el Estado no reconoce el derecho a la autodeterminación no nos podemos supeditar a un diálogo que no se producirá" ${ }^{34}$. En este sentido, la interpretación

\footnotetext{
${ }^{30}$ EFE, "100 personalidades catalanas apoyan una consulta independentista en Barcelona", en 20 minutos, 9 de febrero 2011. «https://www.20minutos.es/noticia/954580/0/consulta/independentista/barcelona/» [Consultado el 26 de abril 2018].

${ }^{31}$ Sobre la relación entre el procés como movimiento extra-parlamentario y su institucionalización, véanse Miley, Thomas Jeffrey, "Against the Thesis of the 'Civic Nation': The Case of Catalonia in Contemporary Spain", en Nationalism and Ethnic Politics, vol. 13, 1 (2007), pp. 1-37. https://doi.org/10.1080/13537110601155734; Dowling, Andrew, The Rise of Catalan Independence. Spain's Territorial Crisis, Nueva York, Routledge, 2018. https://doi.org/10.4324/9781315570969; Crameri, Kathryn, "Political Power and Civil Counterpower: The Complex Dynamics of the Catalan Independence Movement", en Nationalism and Ethnic Politics, vol. 21, 1 (2015), pp. 104-120. https://doi.org/10.1080/13537113.2015.1003491

${ }^{32}$ Jòdar, Jùlia de y David Fernández, Cop de Cup. Viatge.. op. cit.

${ }^{33}$ Ibidem.

${ }^{34}$ Piñol, Àngels, "La CUP exige a ERC y Puigdemont que detallen su programa de gobierno republicano", en El País, 10 de enero 2018. «https://elpais.com/ccaa/2018/01/10/catalunya/1515588594_373278.html» [Consultado
} 
que la CUP hacía sobre el momento de excepcionalidad democrática era la más literal de todos los partidos.

Es evidente, entonces, que la reivindicación del pueblo catalán mediante la noción de excepcionalidad democrática no es exclusiva de la izquierda radical, pero aun así la CUP consiguió mantener una posición radical. Podemos ofrece una perspectiva curiosa sobre este "momento de excepcionalidad" en el sentido de que busca de forma perfectamente deliberada la imposición de sus visiones políticas sobre las demás a través de los momentos de excepcionalidad que les otorgan vigencia. Pablo Iglesias, el líder del partido, argumenta que "political truth is always unilateral [...] it is imposed by victors on the vanquished in moments of exceptionality" 35 , haciendo eco otra vez de la perspectiva del discurso crítico sobre la política. Aunque Iglesias aplica la palabra en un sentido y un contexto distintos a los que se emplean aquí, la lógica de creación de fronteras políticas es esencialmente la misma.

Podemos nació de un descontento no disimilar del que, como hemos visto, la CUP ha sabido articular. Joan Culla, en su recorrido histórico de la CUP, propone que los buenos resultados que el partido obtuvo en las elecciones municipales de 2011 fueron consecuencia de la dinámica entre la indignación del 15-M y el discurso antisistema de la izquierda: el $15-\mathrm{M}$ “connectà amb l'esperit i el tarannà de la CUP, en la mesura que es revoltava contra l'establishment politíc i exigia un canvi de paradigma econòmic" ${ }^{36}$. Según Emmy Eklundh, Pablo Iglesias e Íñigo Errejón se llevaron de la obra de Laclau la idea de que el pueblo no solo se podía articular, sino que este proceso de creación de un pueblo es necesario para cualquier proyecto político ${ }^{37}$. Es un giro discursivo en el que la noción de la gente se justifica no en unas raíces históricas necesarias, sino en la capacidad de expresar una demanda política lo más convincente posible. De ahí que la ambición de Podemos fuera construir "the widest possible popular base" "38; una base relativamente independiente de antepasados ideológicos y siempre imaginada, pero no por ello menos potente. Una de las conclusiones más interesantes sobre el discurso del 15-M que presenta Íñigo Errejón es que parte de su alcance tiene que ver con su capacidad de subvertir la dicotomía tradicional de izquierda-derecha, reivindicando los "casos" específicos de personas que han sido reprimidas no por la derecha, sino "los de arriba" 39 . El proyecto de los indignados se convierte de la misma manera en un proyecto particular en el sentido de que siempre se remite a la injusticia de casos específicos. Si tiene un valor universal es a través de la injusticia cometida contra el individual, y por esta razón evita la limitación que tenía el "plano ideológico" de la izquierda tradicional: "[Los contenidos ideológicos] ya eran expresados por la izquierda minoritaria, pero confrontaban sobre un plano ‘ideológico' con el

\footnotetext{
el 7 de mayo 2018].

${ }^{35}$ Booth, Josh y Patrick Baert, The Dark Side of Podemos? Carl Schmitt and Contemporary Progressive Populism, Londres, Routledge, 2018, p. 92. https://doi.org/10.4324/9781351212557

${ }^{36}$ Culla, Joan, El tsunami. Com i per què ... op. cit., p. 137.

${ }^{37}$ Eklundh, Emmy, "Populism, Hegemony and the... op. cit., pp. 139-140.

${ }^{38}$ Agustín, Óscar García y Marco Briziarelli (coords.), Podemos and the New... op. cit., p. 15.

${ }^{39}$ Errejón, İñigo, “El 15-M como ... op. cit., p. 136.
} 
consenso transversal, y por ello tenían una capacidad de agregación limitada"40. Esto explica que la Diada en 2012 fuera la “contraprogramación del régimen contra el 15-M”, según argumenta el sociólogo Martín Alonso ${ }^{41}$. Es lógico pensar que, dentro del movimiento independentista, se consideraba en el 15-M no solo un potencial obstáculo a los objetivos del procés, sino también una competencia a nivel simbólico. En su conversación Construir pueblo, publicada en 2015, Íñigo Errejón y Chantal Mouffe comentan el potencial del populismo de izquierda a través de la noción de "radicalización democrática"42. La necesidad de un populismo de izquierda viene de la falta por parte del centro-izquierda de desafiar el capitalismo globalizado que está creando sociedades marginalizadas del poder. No puede haber pueblo si no es a través de una radicalización democrática; esta radicalización solo puede darse en una confrontación con este estado. La CUP no tiene la misma visión que Podemos a la hora de institucionalizar el proceso de radicalización democrática, no tiene una "teoría del poder". Sin embargo, como hemos visto, la CUP ejerció una práctica política que se tradujo en éxito electoral sobre todo en 2015. Aunque no subvirtió el proyecto independentista para convertirlo en un proyecto anticapitalista, hizo ver a la izquierda catalana que el independentismo más radical era compatible con el discurso de izquierda. Alfred Bosch de ERC, y consejero actual de Acción Exterior de Cataluña, dijo ya en 2012 que la "experiencia” de la CUP servía como inspiración para la renovación de la ERC, cuya posición en la izquierda y sobre la cuestión de la independencia, como señala Anwen Elias, ha variado bastante desde los años ochenta ${ }^{43}$.

\section{El pueblo catalán como respuesta al sentido común}

Las elecciones de 2017 llegan en un momento extraordinario para la CUP. Es evidente que la colaboración en los últimos años entre la CUP y el centro-derecha independentista conlleva una serie de contradicciones. Diego Alonso dibuja un compromiso político en que la "respetabilidad" de Artur Mas resultó "indispensable" para que la izquierda adquiriera un alcance más allá de los núcleos en los que anteriormente se había basado, mientras que la izquierda a su vez legitimó a Mas como un "demócrata coherente enfrentado a un Estado represivo"44. Esta relación algo contradictoria ha resultado un desafío para la CUP en la medida en que la ha

\footnotetext{
${ }^{40}$ Ibídem, p. 132 .

${ }^{41}$ Molina, Fernando y Alonso Quiroga, “¿Una fábrica de independentistas? Procesos de nacionalización en Cataluña (1980-2015)”, en Forti, Steven et al. (coords.) El proceso separatista ... op. cit., p. 63.

${ }^{42}$ Errejón, Íñigo y Chantal Mouffe, Construir pueblo. Hegemonía y radicalización de la democracia, Barcelona, Icaria, 2015.

${ }^{43}$ Elias, Anwen, "Catalan Independence and the Challenge of Credibility: The Causes and Consequences of Catalan Nationalist Parties' Strategic Behavior”, en Nationalism and Ethnic Politics, vol. 21, 1 (2015), pp. 83-103. https:// doi.org/10.1080/13537113.2015.1003490

${ }^{44}$ Ibídem, p. 196.
} 
obligado a replantearse sus ideales socialistas en función del proyecto independentista. El propio partido en su programa electoral para las elecciones del 21 de diciembre en 2017 asegura que "probablement, durant la darrera legislatura, la CUP-CC també hem interioritzat el discurs de la gestió de la misèria com a mal menor" ${ }^{\prime 5}$. El programa electoral de la CUP estuvo condicionado en cierta medida por la aplicación del 155 , pero también es verdad que su contenido no se refiere solamente a este capítulo específico de la crisis política. Puede que su argumento se nutra de él, pero veremos que los puntos más importantes son otros. En este sentido, no se trata de un discurso excepcional, aunque cargue sentido de la "excepcionalidad" de la situación política en 2017. Esto en sí dice algo de la relativa continuidad del discurso de la CUP a lo largo de los últimos años. Como se mencionaba en la introducción, Barberà y Díaz-Montiel hacen hincapié en que el partido ha mantenido su "complejidad organizativa" en el proceso de transición a las instituciones políticas en Cataluña. Esto también tiene un impacto determinante sobre la política del partido: "la complejidad de la CUP [...] ha limitado sustancialmente las respuestas políticas y organizativas que se han podido adoptar" ${ }^{\text {"46. }}$. Veremos más concretamente sobre qué fundamento normativo se expresan estas respuestas políticas.

El programa electoral del partido en 2017 se permite extenderse, no solo en cuanto a argumentos o propuestas políticas, sino también a la hora de poner una narrativa más elaborada si se compara, por ejemplo, con apariciones en debates televisivos o entrevistas. En el programa aparece desde el principio una relación causa-efecto entre la "crisis económica" o simplemente “capital" como totalidad, y "la vida de milions de persones, i també per a l'entorn natural". Así se mantiene una imagen reconocible en la izquierda radical, en la que el capitalismo constituye un "otro" en la medida en que se que se establece como parte inherente del "sentido común" de la época. Luc Boltanski y Ėve Chiapello describen cómo el capitalismo de las décadas más recientes - un nuevo espíritu del capitalismo - destaca por su capacidad de adaptarse a sus propias críticas ${ }^{47}$. Los "espíritus" del capitalismo pueden entenderse como zeitgeist, rasgos culturales históricos que conllevan y justifican toda una serie de prácticas sociales que están en concordancia con el principio del capitalismo, es decir, con la libre transacción de dinero. En este sentido los espíritus del capitalismo no se pueden reducir a una ideología específica, sino que son muestras históricas de la capacidad del capitalismo de justificarse a sí mismo. Boltanski y Chiapello ponen de evidencia que el espíritu de austeridad que describió Max Weber se fue reemplazando por rasgos de individualismo y "democratización" del trabajo. Como dicen Cazdyn y Szeman, el éxito del capitalismo está en la idea de que sus fallos no son inherentes a él como sistema económico, sino excepciones de su funcionalidad ${ }^{48}$. La idea que exponen

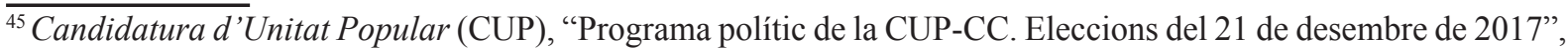
2017, p. 13. «http://cup.cat/sites/default/files/programaelectoralcup21d.pdf» [Consultado el 20 de abril 2018].

${ }^{46}$ Barberà, Óscar y Alberto Díaz-Montiel, "Ho volem tot!... op. cit., p. 184.

${ }^{47}$ Boltanski, Luc y Eve Chiapello, "The New Spirit of Capitalism", en International Journal of Politics, Culture and Society, 18 (2004), pp. 161-188. https://doi.org/10.1007/s10767-006-9006-9

${ }^{48}$ Cazdyn, Eric e Imre Szeman, After Globalization, Malden, Miley-Blackwell, 2013.
} 
Boltanski y Chiapello es que el capitalismo, históricamente, ha sabido "incorporar" las críticas que se le han opuesto. Veremos cómo la CUP intenta ofrecer una alternativa radical a la cara del capitalismo tal y como se presenta hoy.

La CUP mantiene su radicalidad a la hora de posicionarse en la izquierda. En su programa electoral, la CUP no se abstiene de lanzar una dura crítica a la "esquerra institucional" que, a pesar de haber conseguido "avenços en polítiques culturals, lingüístiques o educatives", ha fallado a la hora de implementar una política social en las "qüestions socioeconòmiques $i$ d'ordinació territorial"49. Si el discurso hegemónico personificado en Artur Mas ha constituido el procés como un proyecto esencialmente continuista con la clase política en Cataluña, la CUP deja muy claro que su procés no solo es de izquierdas, sino que sólo puede ser de izquierdas: el "procés d'autodeterminació", de acuerdo con su "proposta política només pot estar vinculat a una millora de les condicions de vida d'àmplies majories socials" ${ }^{50}$. Por eso no es sorprendente, aunque sí llamativo, que describan su política social como un "pla de xoc"51, necesariamente rupturista con respecto tanto de la política anterior como del marco jurídico dentro del cual el Gobierno catalán se ha mantenido, según la CUP.

Por otro lado, el uso de nominalizaciones refuerza el argumento del programa al llevar la narrativa a un nivel más abstracto. Según Michael Billig, "las nominalizaciones tienen las 'funciones ideológicas' de suprimir agencia; (b) cosificar o realizar; (c) presentar objetos realizados como agentes, y por último mantener relaciones desiguales de poder" ${ }^{\prime 52}$. Aunque el “capital" no es literalmente la nominalización de un verbo, hace referencia a algo cuya definición casi solo puede ser un proceso: la libertad de hacer transacciones de dinero. Pero al juntar toda esta pluridad de acciones en la palabra "capital", este se realiza y consigue la apariencia de "algo objetivo" 53 . Se "suprime" agencia en el sentido de que no se identifican agentes concretizados en personas u organizaciones. Así, la agencia se desplaza a estados y procesos abstractos y, por tanto, más adecuados a un discurso populista como es el de la CUP. Por otro lado, vemos la misma forma de materialización de agentes a través de las nominalizaciones: "lucha de liberación", "movilización popular", “dinámica movilizadora", la "represión” de las mayorías sociales, la "mejora de las condiciones de vida de amplias mayorías sociales" que marcan el texto. El uso de nominalizaciones hace que el (anti)discurso se eleve a una esfera abstracta en la que las "fronteras" aparecen muy claras justo porque no se concretizan.

La CUP manifestó que asumiría una táctica de "vot de bloqueig"54 o "acciones de hackeo" — como dijo la exdiputada Mireia Vehí según El País ${ }^{55}$ - si el Parlament, después

\footnotetext{
${ }^{49}$ Ibidem.

${ }^{50}$ Ibídem, p. 9.

${ }^{51}$ Ibídem.

${ }^{52}$ Billig, Michael, "The language of critical discourse analysis: the case of nominalization", en Discourse \& Society, 19 (2008), pp. 783-800. https://doi.org/10.1177/0957926508095894

${ }^{53}$ Ibidem.

${ }^{54}$ Candidatura d'Unitat Popular (CUP), "Programa polític de la CUP-CC ... op. cit., p.12.

${ }^{55}$ Andrés, Guillem, "La CUP boicoteará el Parlament si pierde el independentismo", en El País, 14 de diciembre 2017. «https://elpais.com/ccaa/2017/12/15/catalunya/1513364094_337787.html» [Consultado el 20 de abril 2018].
} 
de las elecciones en 2017, no se optaba por la vía unilateral. Y es con el mismo lenguaje que se interpreta la evolución en la última mitad de 2017: el referéndum del 1-O y las huelgas generales "indiquen que el nivell de consciència popular superava de molt els límits en què aquest sobiranisme al poder l'havia volgut enclaustrar" ${ }^{\text {" }}$. Conciencia popular" son palabras que suponen un "despertar", una toma de acción frente a la impasibilidad de lo "enclaustrado", y la acción debe necesariamente tener lugar al nivel "popular" del pueblo catalán. Podríamos decir que la causa nacionalista aquí se expresa no solo como la voluntad popular, sino como el propio medio de expresión que está a disposición para el pueblo. La "causa popular" se justifica y constituye literalmente en su función de causa nacional. La reacción social y política de los últimos meses de 2017 se establece entonces como una "movilización popular"57. La huelga general del 3 de octubre fue el resultado de varios actores muy distintos, entre organizaciones políticas, civiles y socioculturales. Fueron varias las voces que articularon una sola voluntad, o esa por lo menos es la interpretación que se ha hecho del acontecimiento. No son varias movilizaciones, sino una. Las conclusiones de la primera parte del análisis sobre la cualidad populista del nacionalismo catalán también valen para la CUP, pero con la diferencia de que aquí no se habla de una movilización cualquiera, sino una popular con toda la historia de confrontación con la élite social y política que esa palabra conlleva en el discurso de izquierda. Es una movilización de todos menos el establishment político: "el Govern se sent incòmode en un context de movilitzacions que cada cop controla menys" $" 58$.

Las elecciones del 21 de diciembre en 2017 supusieron un paso atrás para la CUP, que perdió 6 escaños. Hubiera sido una conclusión lógica que el mayor grado de responsabilidad que suponía tener diez escaños después de las elecciones de 2015 hubiera presionado al partido a suavizar su retórica. Esto, por lo que acabamos de ver, no fue el caso. Barberà y Díaz-Montiel proponen que, mientras que entre 2012 y 2015 el partido siguió "una típica política tribunicia de denuncia de la corrupción y de las políticas de austeridad", y que el partido "sólo acomodó muy parcialmente su estrategia para incorporarse a las iniciativas del secesionismo mayoritario", los años que siguieron se marcaron por más tensiones internas y menos énfasis en problemáticas sociales $^{59}$. El programa electoral en 2017, en este sentido, puede interpretarse como una afirmación de la posición del partido como la alternativa más clara de la izquierda tradicional.

\footnotetext{
${ }^{56}$ Candidatura d'Unitat Popular (CUP), "Programa polític de la CUP-CC ... op. cit., p. 10.

${ }^{57}$ Ibídem, p. 12.

${ }^{58}$ Ibídem.

${ }^{59}$ Barberà, Óscar y Alberto Díaz-Montiel, "Ho volem tot!... op. cit., p. 182.
} 
6. Conclusiones. ¿Un futuro de radicalidad para la izquierda catalana?

Una de las cuestiones centrales en la brecha que representa la "nueva izquierda" o populismo de izquierda de la que forma parte Podemos es la metáfora de la dicotomía izquierdaderecha. Más allá de la precisión que la que se pueda describir la realidad, ¿hasta qué punto la dicotomía sirve para movilizar y unir a un "pueblo"? Íñigo Errejón, en su conversación con Chantal Mouffe, se muestra algo pesimista con el potencial movilizador de reivindicar la clase trabajadora en España ${ }^{60}$. Según su interpretación, la metáfora pertenece a una lengua y práctica política que no corresponden ni a las demandas diversas de la población ni a las dinámicas antagonistas del campo político. La imagen antisistema se vuelve anticuada si no se acompaña por una voluntad explícita de formar parte de dicho sistema para así plantear la pugna contrahegemónica: "En la medida en que se lo ve más como una máquina que como un campo de fuerzas [...] el Estado solo puede ser aceptado o rechazado como un todo" "61. Queda claro que la CUP, incluso en su momento de mayor influencia, no abandonó este lenguaje rechazado por Podemos. Sin embargo, el lenguaje no solo ha resultado convincente para una parte importante de la población, también aparece coherente según la lógica del populismo de izquierda descrito por Chantal Mouffe. Albert Botran i Bahissa, historiador y político de la CUP, describió en una entrevista con El 9 Nou en 2012 la visión del partido: "Unitat Popular és aglutinar una sèrie de reivindicacions de millora social per a la majoria de la població en una estratègia política concreta, que en aquest cas és la independentista. És a dir, la necessitat d'obrir la porta a la llibertat per instaurar una sèrie de polítiques que deixin enrere les desigualtats $i$ les injustícies" ${ }^{2}$. La aportación de la CUP en los últimos años, especifica Botran, es llevar el proyecto social siempre como uno de radicalización democrática: "Si prioritzem més un eix que l'altre, ens estem posant travetes a nosaltres mateixos. Si hem arrelat i tenim alguna cosa a aportar en la història d'aquest poble és tenir clar que aquests dos processos van junts"63.

Podríamos decir que lo hicieron, y de una forma convincente para el resto de la izquierda catalana. La heterogeneidad y estrategia del partido son incompatibles con el tipo de populismo de izquierda que Podemos busca realizar. Y, sin embargo, han expresado sus dudas acerca del proyecto político de Podemos. Agustín y Briziarelli argumentan que "the fundamental question of whether Podemos can embrace concrete labor and class issues without compromising its middle-class-centered transversalism remains unanswered"64. Emmy Eklundh también se muestra preocupada de que, si el partido se apoya demasiado en una imagen transversal del

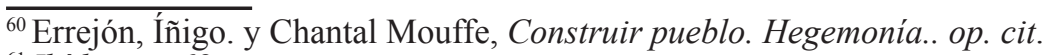

${ }^{61}$ Ibídem, p. 69.

${ }^{62}$ Comajoan, Josep, "La independència només s'imposarà si va lligada a conquestes socials", en El 9 Nou, 24 de septiembre 2012. «http://manlleu.cup.cat/document/entrevista-albert-botran» [Consultado el 8 de junio 2019].

${ }^{63}$ Ibídem.

${ }^{64}$ Agustín, Óscar García y Marco Briziarelli (coorda.), Podemos and the New... op. cit., p. 8.
} 
pueblo español, el contenido de su crítica social se diluya ${ }^{65}$. La interpretación que se puede hacer del rol de la CUP y la izquierda radical en el procés es que, a pesar de las incomodidades y tensiones internas entre las militancias, fue instrumental en la construcción de un nacionalismo rupturista y fue complementario en la formación de un antidiscurso radical de la izquierda. La CUP lleva a una vuelta exitosa al plano izquierda-derecha que no desatiende a la indignación social, sino que la potencia. Las conclusiones de este análisis pueden indicar que la CUP ha sido capaz de asumir el descontento social que representa y lo ha traducido en un discurso coherente por su radicalidad. La CUP fue capaz de expresar un descontento social a través de un nacionalismo que se reinsertó en la dicotomía izquierda-derecha y la adecuó al conflicto histórico que estaba y está viviendo Cataluña.

En el análisis no se incluyen los resultados de las elecciones municipales en 2019, que resultaron una gran decepción para la CUP, ya que no llegó al $5 \%$ requerido para tener representación en el Ayuntamiento de Barcelona. Estos resultados, junto con los de las elecciones parlamentarias en 2017 , hacen dudar del proyecto rupturista de la izquierda, y más teniendo en cuenta el éxito del independentismo de centro-derecha de Carles Puigdemont en 2017. Por otra parte, la colaboración entre Barcelona en Comú, el PSC y Manuel Valls para reinvestir a Ada Colau como alcaldesa de Barcelona en 2019 provocó fuertes reacciones desde las listas independentistas. ERC, en cambio, vuelve a ocupar una posición importante tanto a nivel parlamentario como municipal, y queda por ver cómo va a manejar la línea rupturista que la CUP formó parte en trazar.

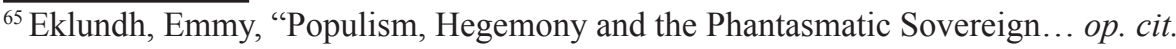

